\title{
Fuzzy Approach to Risk-Controlling in Oil and Gas Company Management
}

\author{
Iryna Fadyeyeva \\ Department of Finance \\ Ivano-Frankivsk National Technical \\ University of Oil and Gas \\ Ivano-Frankivsk, Ukraine \\ https://orcid.org/0000-0002-6978-1621
}

\author{
Oksana Gryniuk* \\ Department of Finance \\ Ivano-Frankivsk National Technical \\ University of Oil and Gas \\ Ivano-Frankivsk, Ukraine \\ https://orcid.org/0000-0001-7390-1174 \\ Svitlana Korol \\ Department of Finance \\ Ivano-Frankivsk National Technical \\ University of Oil and Gas \\ Ivano-Frankivsk, Ukraine \\ https://orcid.org/0000-0002-4804-7612
}

\author{
Ilona Mandryk \\ Department of Finance \\ Ivano-Frankivsk National Technical \\ University of Oil and Gas \\ Ivano-Frankivsk, Ukraine \\ https://orcid.org/0000-0001-6122-6036
}

\begin{abstract}
The article is devoted to the development and improvement of methodology and implementation of riskcontrolling subsystem in the management system of oil and gas companies in under uncertainty conditions. It is proved, that the mathematical tool of Fuzzy Logic allows to reveal and take into account complicated nonlinear dependences between quantitative and qualitative indicators of risk-event probability estimation, and also mutual effect of risk forming factors. The six-level system of evaluation of risks of operating activities of oil and gas companies, based on fuzzy logic has been established. It allows to take into account the non-linear nature of the relationship between the risk forming factors and the resulting indicator. The logical inference model has been designed. It shows the dependence of the risk level on the meaning of linguistic rules about groups of risk forming factors in different risk groups and which is the basis for the risk assessment model. The conceptual model of management of oil and gas companies with the risk-controlling subsystem as a part of it, the main element of which is the fuzzy model of risk assessment and forecasting, has been proposed. The research concluded, that the implementation of the proposed model of management of oil and gas production enterprises will significantly improve the efficiency of the upstream segment enterprises and significantly reduce losses, caused by the occurrence of risk-events.
\end{abstract}

Keywords-controlling, risk, risk-controlling, risk assessment, fuzzy logic, risk-controlling subsystem, oil and gas company, management system

\section{INTRODUCTION}

Ensuring the flexibility of the enterprise management system to respond to changes in the internal and external environment is one of the priority tasks for oil and gas companies. Current operating conditions of oil and gas companies are characterized by uncertainty, which is caused by the dynamics of the external and internal environment. Uncertainty leads to risks, which are various in forms, frequency and nature, necessitate investigation of their cause and effect relationships. Well functioning of the risk management system of oil and gas company based on the integration of the risk-controlling subsystem into the system of its management can be considered as a factor of improvement of the efficiency of enterprises activity, which will allow to form the prerequisites for maintenance and intensive increasing of the level of hydrocarbon extraction and reducing of its cost-price.

The company's management in a dynamic risk environment should focus not only on maintaining its position in the market, but also on ensuring its sustainable strategic development. Just controlling within the framework of the concept, focused on the system of crisis management and sustainable development, is aimed at searching weak signals of possible crisis situations and timely elimination of bottlenecks and deviations.

The necessity to identify the reasons for deviations of actual indicators from planned ones implies the time lag between the occurrence of the adverse event and the response to it, which does not allow to make corrective actions in the conditions of uncertainty and rapid change of disturbing factors timely. It should be noted that the main reason of non-effective functioning of the risk management subsystem may also be its imperfect, incomplete integration into the management system of oil and gas companies.

Considering the novelty of risk-controlling concept, the fragmentary nature of its research, it is necessary to form a comprehensive approach to development and improvement of the methodology of forming and implementation of the risk-controlling subsystem in the management system of the oil and gas company.

Under conditions of the permanent uncertainty of external and internal environment of oil and gas companies, this problem has become an important independent scientific and applied value.

\section{REVIEW OF LITERATURE}

The problem of effective risk management [1] has been actively researched by many scientists. The most of researches concern banking, stock, currency, credit, environmental risks [2], as well as innovation risks [3, 4]. At the same time, the procedures of risk assessment of industrial enterprises are being investigated [5]. 
It is proved that estimation and determination the level of their influence on the economic situation of the company is a complicated multifunctional process. Even more complicated are the risks of oil and gas companies effects [6], methodological approach to their evaluation is considered in $[7,8]$. However, now there is no common methodology for assessing the level of risks effects on the oil and gas companies activity and ensuring their sustainability.

This problem is of great importance now because there is an urgent need to develop methodological bases for creating an effective system of managing [9] the economic risks of business activity of companies [10]. As there is currently no comprehensive theory of risk management, [11] methods for the practical detection, identification and assessment of risks for processes of the upstream business segment are being developed.

The analysis of the latest researches in risk management of the upstream business segment [2 $\div 5]$ shows that in the development of their management systems $[9 \div 11]$ there is a tendency towards intellectualization. It is connected with the expansion of the range of tasks that are need to be solved and also the need to ensure a high level of adaptation of the control systems to the specifics features of the objects and to changes the conditions of their activity.

The traditional paradigm and upstream business segment management systems do not provide identification and risk management, as well as real-time coordination of subsystems. The control systems of different management levels solve mainly accounting and reporting problems, but the systems do not contain technical and economic models and methods of analysis and control, powerful tools of optimization are not used.

Whereas the ideological basis for the development of integrated automated management systems for oil and gas companies is effective enclosed technical and economic risk management in particular, the solution lies in the structuring and description of production, processes, objects, production flows and expences, and their corresponding risks that arise in this environment, the design of technical and economic models and management techniques, as well as their implementation on the basis of modern intellectual technologies.

Management decisions and especially non-correct ones have high cost in upstream business segment [11]. That's why development and improvement of methodology for design and implementation of risk-controlling subsystem in management system of an oil and gas company is a relevant scientific and applied problem.

\section{PURPOSE}

Improving the efficiency of management system of oil and gas companies by creating in their structure riskcontrolling subsystem with Fuzzy-model of risk assessment and forecasting as the main part.

\section{THE RESUlts}

Being the component of the controlling system, the riskcontrolling subsystem is aimed to establish and support the functional capability of the risk management system of oil and gas company.
However, implementation of the risk-controlling subsystem is possible only if there are certain tools that can provide to achieve the goal. In order to accomplish determined tasks, the risk-controlling subsystem must operate both risk management tools and standard tools of operational and strategic controlling. Controlling tools, suggested in $[1 \div 5]$ are most often related to its objectoriented type, i.e., the controlling subsystem.

The specific risk-controlling tools used are: Cash Flow at Risk (CFaR), Theory of Fuzzy Sets and Fuzzy Logic, RiskBased Budgeting, Modified Balanced Scorecard (BSC), Value at Risk (VaR)

In order to improve the efficiency of the risk management subsystem, it is suggested to use two following risk-controlling methodological tools.

Thus, taking into account that risk factors of oil and gas companies are highly uncertain, the application of a conceptual approach based on Fuzzy Logic tools is suggested for the analysis of their impact on the operational activities of business entities and for the construction of a model for assessing and forecasting their risks [14].

The information, received at the system input, is transformed in such a way, that the setting of linguistic variables allow to determine the control rule and linguistic variable, which correspond to the initial value of the Fuzzycontroller.

Processing of input information consists of the following main procedures:

- Fuzzification, i.e. establishment of linguistic variables $X$ and their membership functions $\mu(x)$, where $x$ is a continuous basic variable; $x \in X ; 0 \leq \mu(x) \leq 1$.

- Inference, i.e. setting of management rules and the linguistic variable, corresponding to the output signal.

- Defuzzification, i.e. transformation of linguistic variables at the output into a continuous signal.

Decision making for management of economic and technical objects is based on two types of Fuzzy-models Mamdani and Takagi-Sugeno [12]. Mamdani-type Fuzzymodel is presented as a set of Fuzzy rules related to each other by "AND" logical operator, which outputs are mutually independent [12]:

$$
R^{(k)}: \text { IF } x_{1} \text { is } A_{1}^{k} \wedge x_{2} i s A_{2}^{k} \ldots \wedge x_{n} \text { is } A_{n}^{k} \text { THEN } y_{m} i s B_{j}^{k},
$$

where $k$ is the number of fuzzy rules;

$A_{i}^{k}$ is the fuzzy sets (linguistic terms) $A_{i}^{k} \subseteq x_{i} \subseteq R, i=1, \ldots, n$; $B_{j}^{k}$ is the linguistic terms $B_{j}^{k} \subseteq y_{1} \subseteq R, j=1, \ldots, m$;

$x_{1}, x_{2}, \ldots, x_{n}$ are input variables of the linguistic model;

$y_{1}, y_{2}, \ldots, y_{m}$ are output variables of the linguistic model.

Note that each input variable $x_{i}$ contains a finite set of linguistic terms with triangular membership function. The number of terms is determined taking into account the span 
of variables by the formula $2 n+1$, where $n$ is the number of ranges within the range of parameter changes.

Pl Fuzzy-rules of Takagi-Sugeno model are based on the concept of consequent as a function of the input values [12]:

$$
\begin{aligned}
& P l: I F x_{1} \text { is } A_{1} \wedge x_{2} \text { is } A_{2} \wedge \ldots \wedge x_{n} \text { is } A_{n} \text { THEN } \\
& z=f\left(x_{1}, x_{2}, \ldots, x_{n}\right)
\end{aligned}
$$

where $A_{i}$ is Fuzzy-set;

$z$ is a real parameter in the form of a function $f\left(x_{1}, x_{2}, \ldots, x_{n}\right)$ of the input parameters $x_{i}$.

Theory of fuzzy sets, as a methodology, allows to improve the accuracy of calculations and business efficiency. With its help it is possible to imitate intellectual activity which is similar to activity of human, by modelling of diverse and complicate objects, to use the incomplete natural language based on knowledge and experience of experts.

Fuzzy methods also allow to implement automated management of business-processes, to form and improve integrated automated management systems and prevent risks that arise in oil and gas companies, which features are large scale, versatility, variability and difficulty forecasting based on accumulated data $[8,11]$.

The second methodological risk-controlling tool for diagnostics deviations of Key Performance Indicators and key risk indicators of oil and gas companies from their critical values is a modified balanced scorecard. It enables prompt decisions to be given to decision-making person to undertake measures aimed at reducing the negative impact of specific risks forming factors on the efficiency of oil and gas companies activity.

Therefore, while designing the model for assessing risks of oil and gas company's operating activities, the relationship between the level of the risk forming factors of the researching groups of risk factors and the general level of risk of the company's activity should be taken into account.

This problem is aggravated by the fact that while making economic management decisions to prevent risks, there is a large number of different information situations, which are understood as a certain degree of uncertainty gradation regarding the position of economic environment in one of its possible states at the time of certain decision-making. Classification of information situations (IS) has been created, of which seven are typical: $\operatorname{Cor}<I_{1}, I_{2}, I_{3}, I_{4}, I_{5}, I_{6}, I_{7}>$.

The first information situation $I_{1}$ is characterized by a given apriori distribution of probabilities $p_{j}$ by states of economic risk-environment, i.e. when the components of vector $P\left(p_{1}, p_{2}, \ldots, p_{n}\right)$ are known, where $p_{j}$ is the probability of implementation of $j$-th state and $\sum_{j=1}^{n} p_{j}=1, p_{j} \geq 0 ; j=1,2, \ldots, n$.

The second information situation $I_{2}$ is characterized by the distribution of apriori probabilities of various states of the economic risk-environment with an accuracy of unknown parameters that characterize this law of distribution.

The third information situation $I_{3}$ is characterized by the fact, that the law of distribution of probability of states of economic risk-environment is apriori unknown, but some correlation of these states ordering are known.

The fourth information situation $I_{4}$ is characterized by:

- Unknown distribution of apriori probabilities of different states of economic risk-environment, provided that unknown probabilities $p_{j}(j=1,2, \ldots n)$

of the scenarios are suitable by the ratio $\sum_{j=1}^{n} p_{j}=1$.

- Absence of an active counteraction of the economic environment to the goals of the management entity.

The fifth information situation $I_{5}$ is characterized by absolutely opposite interests of decision-maker and economic environment.

The sixth information situation $I_{6}$ is characterized as intermediate one between the situations $I_{1}$ and $I_{5}$ when the economic environment is selected as its own states, when the economic environment is not passive simultaneously with the availability of information on the distribution of apriori probabilities. The contradictions between the interests of the decision-maker and the economic environment are not necessarily completely antagonistic.

The seventh information situation $I_{7}$ is characterized by the Fuzzy-set of states of economic risk-environment.

Each information situation corresponds to its own choice of criteria for decision-making, which is understood as a certain indicator of economic efficiency and algorithm that allows to choose the only optimal solution $S_{\text {opt }} \in S$ from a set of decisions $S=\left(s_{1}, s_{2}, \ldots, s_{m}\right)$ for a fixed assessment functional in the field of a specific information situation in accordance with this economic indicator.

However the unresolved part of the determined scientific problem is the creation of a quantitative measure of assessment of uncertainty in business-processes and riskenvironment of oil and gas companies, functioning under apriori and current uncertainty.

Known Gibbs-Janes' principle of maximum uncertainty allows to receive an estimation of apriori distribution of probability of states of the economic environment in fields of information situations $I_{3}$ and $I_{4}$ which are typical for oil and gas companies. Therefore, the estimation of apriori distribution should be based on appropriate hypotheses. Such a hypothesis may be the principle of maximum uncertainty of Gibbs-Janes or the principle of insufficient reasons of Bernoulli-Laplace.

The authors of the Gibbs-Janes' principle used the entropy of K. Shannon as a measure of the uncertainty of economic environment behavior [15]: 


$$
H(P)=-\sum_{j=1}^{n}\left(p_{j} \ln p_{j}\right)
$$

where $P\left(p_{1}, p_{2}, \ldots, p_{n}\right)$;

$p_{j}$ is the probability of implementation of the $\mathrm{j}$-th state of economic environment and at the same time $\sum_{j=1}^{n} p_{j}=1, p_{j} \geq 0 ; \quad j=1,2, \ldots, n$.

However, in our opinion, it is expedient to replace the concept of the quantity of information according to K. Shannon by the concept of "pragmatic value" of economic information. That is if one of the probabilities $p_{j}$ is equal to 1 , and other probabilities are equal to 0 , that is, one result is reliable and there is no any uncertainty, the pragmatic value of economic information is equal to 0 . When probabilities $p_{j}$ are equal and there is the greatest uncertainty, the pragmatic value of information is maximum. When the state of the economic environment has two equally probable results, the pragmatic value of economic information is equal to 1 .

The pragmatic value of economic information $H(P)$ depends on the probabilities of individual states of the economic environment.

The maximum rate of pragmatic value of information in the risk-environment (the level of maximum uncertainty) can be determined by the following criteria [15]:

$$
H(P) \underset{p \in \Delta p}{\longrightarrow} \max
$$

or

$$
\left(-\sum_{j=1}^{n} p_{j} \ln p_{j}\right) \underset{p \in \Delta p}{\longrightarrow} \max
$$

where $\sum_{j=1}^{n} p_{j}=1, p_{j} \geq 0 ; j=1,2, \ldots, n$ is limit.

Thus, for a quantitative estimation of uncertainty of riskenvironment in the oil and gas industry it is expedient to use pragmatic value of technical and economic information that allows to apply a principle of the maximum uncertainty of Gibbs-Janes for making management decisions under unknown distribution of probability of states of this environment.

Based on the results of the analysis of pragmatic value of information regarding risk events at the business entities under investigation, we have identified six groups of risk forming factors, that have a negative impact, and design structure of the six-level risk assessment model of the operating activity of oil and gas companies based on Fuzzy Logic [13].

At the first level of the system using Fuzzy Logic production and technological risk factors are assesses on the basis of "pragmatic information" about the probability of risk forming factors. The obtained results are delivered to the second level of the system, where the level of risk, which carry two groups of risk forming factors (group of production and technological risks and group of personal risks), are assessed using Fuzzy Sets theory. This procedure is carried out at 3-5th levels, gradually taking into account "pragmatic information" about the probability of occurrence of all risk groups. At the sixth level determanation of the level of risk of operative activity of oil and gas company is performed.

The application of designed six-level model allows to:

- Take into account the non-linear nature of the relationship between the reseached risk forming factors and the resulting indicator (risk level of the operational activities of oil and gas production enterprises).

- Consider both qualitative and quantitative parameters while assessing the level of risk.

It allows to use the designed model as one of the major elements in the automated management systems of oil and gas companies.

The task of management is to achieve the most advantageous ratio between input and output, which determines the efficiency of the system, or rather its economic efficiency.

The quality of functioning of any system is evaluated by comparing its output $Y$ with input $U$. The automated management enterprise systems of oil and gas companies considers the case, when the active agents - resources $U$ act at the input of the system - the target product $Y$ and the efficiency $E$ is determined by the ratio of the output gain $\Delta y$ to the input gain $\Delta x$, i.e. as a specific output per input unit, which is maximized during the system optimization:

$$
E=\Delta y / \Delta x \rightarrow \max .
$$

At such interpretation efficiency characterizes the system considered from the point of view of its effect on labor productivity.

In other cases, the output and input of the system can be represented in the same units, for example, in monetary ones. Then it is more convenient to compare the output and input of the system, maximizing their substraction, that is, the profit $N P$ :

$$
N P=(Y-U) \rightarrow \max .
$$

As follows from the last two formulas, the increase in the efficiency of the system in specific cases can be achieved either by increasing the amount produced at its output (criterion) under specified resource consumption at its input (limit), or by reducing the resource consumption at input (criterion) while the specified amount produced at its output (limit: plan).

It should be noted that using formulas (6) and (7) it is possible to record a short-term effect. However, economic systems in the upstream segment are insensitive to such short-term results. They should function effectively over long periods of time on average. In addition, such models do not take into account the impact of risk forming factors and losses, that may be incurred in the couse of a risk event. Therefore, in such systems it is advisable to use [15] 
sustainable results and efficiency $W$ as an economic criterion of management, which is the sum of $1=\overline{1, n}$ at discrete stages of operation time of the system $t$, and sum of $j=\overline{1, m}$ components of the multipurpose criterion $E$, which also takes into account the risk component. The components are taken with weights $B_{j}$, that take into account their importance and are determined by experts:

$$
W=\sum_{i=1}^{n} \sum_{j=1}^{m} B_{j} E\left(t_{i}\right) \rightarrow \max
$$

It is proposed to supplement the existing model with an economic and mathematical model of the enterprise with synergistic relationships between its components, and which reflects the influence of internal and external economic factors on the dynamics of the system.

If vector $\overline{X^{T}}(t)$ characterizes the economic state and activities of oil and gas company in month $t$ :

$$
\overline{X^{T}}(t)=\left(N P_{t}, K_{t}, K A_{t}, Q_{t}\right)
$$

where $N P_{t}$ is accumulated profit for $t$ months;

$K_{t}$ is accumulated equity capital of the oil and gas company; $K A_{t}$ is invested (accepted) capital of oil and gas company, accumulated over $t$ months;

$Q_{t}$ is production output of oil and gas production company, then vector $Y=Y(X, t)$ combines external and internal economic factors influencing the dynamics of the system as a whole:

$$
\bar{Y}(\bar{X}, t)^{T}=\left(V_{t}, p_{t}, f_{t}, f s_{t}, s c_{t}, l_{t}, L_{t}, r_{t}, D_{t}, \eta_{t}, \alpha_{t}, \beta_{t}\right),
$$

where $V_{t}$ is the price at which the oil and gas company sells its products (transfer price);

$p_{t}$ is the selling price of production unit (1 ton of oil or $1,000 \mathrm{~m}^{3}$ of gas);

$f_{t}$ is the monthly fixed overheads;

$f s_{t}$ is the Fuzzy-Logic risk-controlling system;

$s c_{t}$ is the variable distribution costs per production unit;

$l_{t}$ is the cost of labor of oil and gas company;

$L_{t}$ is the size of primary production personnel of oil and gas company;

$r_{t}$ is the the coefficient associated with percent-denominated demand growth per one year of operation of the enterprise (the value $r$ equals to the percentage of demand growth during the first year of operation when $D_{\max }=2$ );

$D_{\max t}$ is the maximum possible multiplicity of growth of demand for products;

$\eta_{t}$ is the coefficient characterizing the production capacity of the company;

$\alpha_{t}$ is the rate of reinvestment of profit in the capital of the company;

$\beta_{t}$ is the capital depreciation rate.
These values are functions that depend both on time and on the vector components listed above $\overline{X^{T}}$.

The performed structural analysis of upstream oil and gas companies as management entities has shown that the most promising is the using of a hierarchical system of integrated management, which is considered as a multi-level structure consisting of interrelated elements and the external environment of the elements, and has a risk-controlling component.

During the research we consider the risk-controlling system as a subsystem of the oil and gas company controlling system, which key projections of implementation are instrumental, methodological and institutional ones.

As a result of modeling in the MathCad, we obtained relationships between the input risk factors and the resulting trait - the probability of a risk event occurring corresponding to risk factor groups. In Fig. 1 it is shown the simulation results for the first and fourth risk groups, as well as the resulting trait. The surfaces for the second and third risk groups are similar.

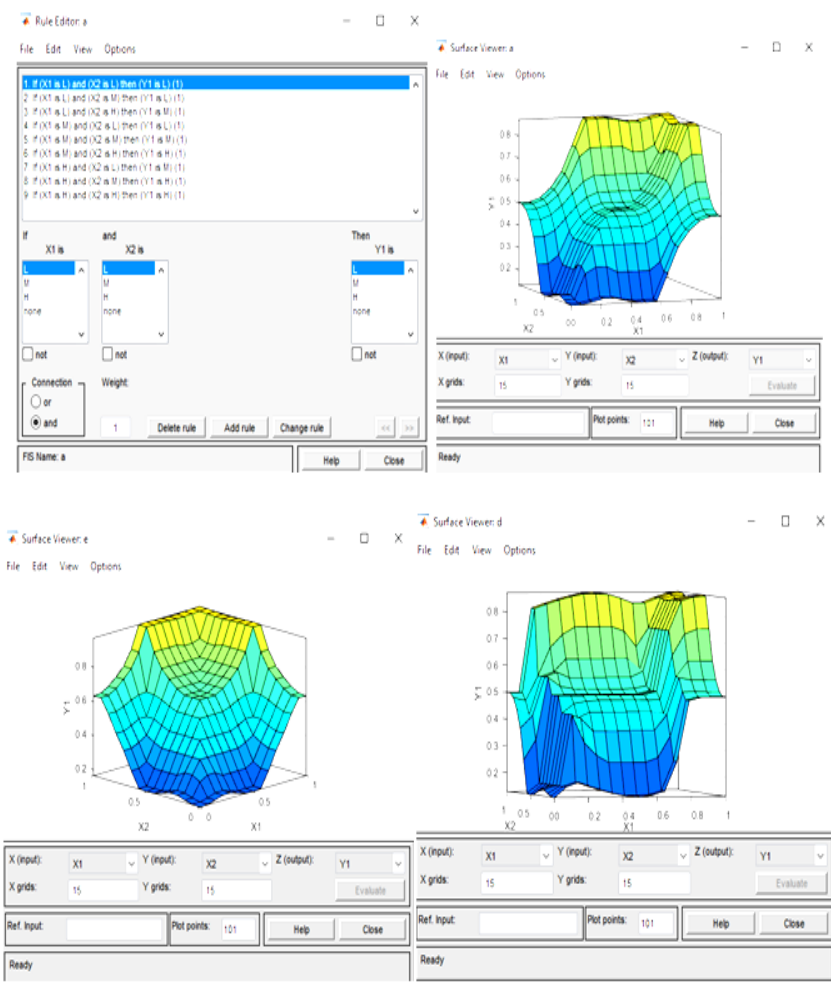

Fig. 1. Results of simulation of the probability of risk event occurrence from different groups of risk factors based on the Mamdani-type Fuzzy-model.

The obtained functions of the response surfaces in the form of a graph show the dependence of the output value on any two input variables. Obtained surfaces represent the partial (of certain pre-selected risk groups: Scope 1, Scope 2, Scope 3, Scope 4) or the general probability of operating risks of oil and gas companies (Scope 5).

The Fuzzy-logic that is the basis of described above risk assessment model enables to identify and account complex of nonlinear dependencies between quantitative and 
qualitative indicators, which, unlike linear models, improves the adequacy of the obtained estimation results. The forecasting error for designed Fuzzy-model is 15\%. This model has been tested in several oil and gas companies, and has shown the adequacy and high convergence of results obtained, which avoided losses of companies more than $\$ 100,000$.

While substantiating the feasibility of implementing the risk-management system into management system of company, the advanced diagnostics of the company activity should be done. However, within the stage of "analysis of existing management system", we consider it is necessary to pay attention first to analysis of the existing riskmanagement system. Based on the information received, all the "bottlenecks" of the company, including risk management ones, should be identified. Thus, the riskcontrolling system model will gradually get clearer form.

The mechanism of risk assessment based on Fuzzy-logic has considerable advantages for adapting it to existing models of risk-management, taking into account real conditions of functioning of oil and gas companies.

\section{CONCLUSION}

Implementation of risk-controlling subsystem influences positively the efficiency of the oil and gas company management system as a whole and is manifested in the following aspects: increase of efficiency of decision-making under unsertainty conditions due to differentiation of riskcontrolling and risk management tasks performed by systems; risk management system is focused on setting goals, tasks, organizational aspects of risk management process, making final decisions regarding reducing the probability of risk and / or its impact on a business entity.

They can be used to solve the tasks of coordinating of subsystems operation in integrated system of management of oil and gas company of the upstream segment.

\section{REFERENCES}

[1] ISO/IEC 31010:2009 Risk management - Risk assessment techniques (IDT).

[2] A. E. Panyagina, "Overview of current risk assessment methods", Economics and management of innovative technologies, vol. 3, 2014.
[Online]. Available: http://www.ekonomika.snauka.ru/ 201/03/3966. Accessed on: August 4, 2019. [in Russian].

[3] A. Nechaev, and A. Prokopyeva, "Identification and management of the enterprises innovative activity risks", Economic Annals-XXI, vol. 5-6, pp. 72-77, 2014.

[4] N. O. Kaverina, "Scientific and methodological approaches to the analysis and risk assessment of innovation activities", Scientific Jornal "Science-Rise", vol. 5, no. 3, pp. 74-75, 2014. [in Russian].

[5] M. V. Nikolaychuk, "Risk-controlling in the system of effective enterprise management", Formation of a market economy vol. 24, pp. 387-398, 2010. [in Ukrainian].

[6] A. Chawather, U. Ozdogan, K. S. Glaser, Y. Jalali, and M. Riding, "Plan for Success in Deep Water", Oilfield Review: Schlumberger, Spring 2009, pp. 26-35, 2009.

[7] I. Khvostina, N. Havadzyn, and N. Yurchenko, "Manifestation of emergent properties in risk assessment of oil and gas companies", SHS Web of Conferences, vol. 65, article ID 08001, 2019. doi:10.1051/shsconf/20196508001.

[8] M.Yu. Nemchenko, "Methodological basis of risk assessment of oil and gas companies", Economical sciences, vol. 10, pp.382-385, 2009. [in Russian].

[9] Y. O. Konovalov, and A. V. Mironov, "Risk management system: concept, functions, components", Innovative economy, vol. 9(47), pp. 127-132, 2013. [in Ukrainian].

[10] N. L. Sydoruk, and A. G. Baldyniuk, "Economic risks management system of enterprise activity", Economical sciences. [Online]. Available:

http://www.rusnauka.com/17_AND_2010/Economics/69266.doc.htm. Accessed on: August 4, 2019. [in Ukrainian].

[11] G. N. Sementsov, "Construction of the support system for decision making management of specific technological risks in the welldrilling process", International Periodic Scientific Journal "Modern engineering and innovative technologies”, issue 7, part 3, pp. 21-36, 2019. [in Ukrainian].

[12] Harpreet Singh, Madan M. Gupta, Thomas Meitzler, Zeng-Guang Hou, Kum Kum Garg, Ashu M. G. Solo, and Lotfi A. Zadeh, "Reallife applications of fuzzy logic", Hindawi Publishing Corporation. Advances in Fuzzy Systems, vol. 2013, article ID 581879, 2018. http://dx.doi.org/10.1155/2013/581879.

[13] I. G. Fadyeyeva, and O. I. Gryniuk, "Fuzzy modelling in risk assessment of oil and gas production enterprises' activity", Baltic Journal of Economic Studies, vol. 3, no. 4, pp. 256-264, 2017.

[14] C. Kahraman, Fuzzy Engineering Economics with Applications. Heidelberg, Germany: Springer-Verlag Berlin Heidelberg, 2008.

[15] I. G. Fadyeyeva, System-Synergistic Basis of Management of Corporate Structured Oil- and Gas-Producing Enterprises. IvanoFrankivsk, Ukraine: PP Kuziv B., 2012. [in Ukrainian]. 